\title{
Conditional Cash Transfers and the Equity-Efficiency Debate*
}

\author{
Jishnu Das Quy-Toan Do Berk Özler \\ The World Bank
}

April 19, 2004

\begin{abstract}
During the last decade, the use of conditional cash transfers to increase investment in human capital has generated considerable excitement in both research and policy forums. Such schemes are being increasingly adopted in a number of contexts and countries to improve outcomes in health, education, and child labor as they aim to balance the goals of current and future poverty reduction. In this paper, we define any scheme requiring a specified course of action in order to receive a benefit as a conditional cash transfer. This definition includes cash transfers based on human capital investments, but is sufficiently broad to encompass other schemes such as workfare programs or consumption transfers.

We examine the rationales behind, the problems with, and the tradeoffs inherent to conditional cash transfer programs. We discuss two main concerns: low participation and fungibility. Low participation refers to the problem of program uptake. If individuals do not participate in the program, whether it was designed to increase human capital investment or to target resources, the program will not be successful. The problem of fungibility, however, depends on the rationale for the particular conditional cash transfer program. When used to increase efficiency, even when program uptake is high, program effects may be less than envisioned due to behavioral responses of households that lead to changes in the consumption of close substitutes. While researchers have typically addressed these issues separately, we emphasize the need for policy-makers to incorporate a number of different factors in a comprehensive framework to design optimal conditional cash transfer schemes.
\end{abstract}

\footnotetext{
*We are grateful to Harold Alderman, Francisco Ferreira, Jed Friedman, Emanuela Galasso, Hanan Jacoby, Michael Kremer, Peter Lanjouw, Martin Ravallion, Carolina Sanchez-Paramo, Adam Wagstaff, and three anonymous referees for comments and helpful discussions. The findings, interpretations, and conclusions expressed in this paper are entirely those of the authors. They do not necessarily represent the view of the World Bank, its Executive Directors, or the countries they represent.
} 


\section{Introduction}

During the last decade the use of conditional cash transfers to increase investment in human capital has generated considerable excitement in both research and policy forums. This paper views any scheme requiring a specified course of action in order to receive a benefit as a conditional cash transfer. The definition includes cash transfers based on human capital investments, but is sufficiently broad to encompass other schemes such as workfare programs or consumption transfers. Such schemes are being increasingly adopted in a number of contexts and countries to improve outcomes in health, education, and child labor. Conditional cash transfer programs aim to balance the goals of current and future poverty reduction. Well-known examples include PROGRESA in Mexico, Bolsa Escola in Brazil and the Red de Proteccion Social (RPS) in Nicaragua. Evaluations have shown that these programs are (a) technically feasible in the sense that the main stated goals of the programs are actually met in practice and (b) politically feasible in that successive governments are willing to continue, and even expand the coverage of these programs. These results have been a source of enthusiasm in the development community for researchers and policy-makers alike.

What explains the current popularity of such schemes? There is ample evidence that households' consumption patterns given an equivalent amount in cash would be very different from the outcome under these schemes: they would consume less of the conditioned-on good and more of other commodities instead. Empirical examples abound. A program in Western Kenya for instance, provided insecticide-treated bed-nets for households to decrease the incidence of malaria (Nahlen and others, 2003). However when asked what they would do if granted an income transfer, household priorities were very different. They would rather have spent the cash on food and clothing, bed-nets remaining a distant priority (Alaii and others, 2000). Also in Western Kenya, Kremer and Miguel (2003a and 2003b) show that a school-based deworming program had large effects on attendance. Nevertheless, a small increase in the price of the pills from its initial level of zero resulted in an 80 percent decline in their use. These results are not specific to Sub-Saharan Africa. In an ex-ante evaluation of Brazil's Bolsa Escola program, which conditions cash transfers on school attendance, Bourguignon and others (2002) argue that cash disbursements given unconditionally would have had no significant impact on school enrollment. Both their ex-ante study and recently available ex-post figures (Cardoso and Souza, 2003) show that the conditionality was critical and successful in increasing school participation.

A rationale for conditionality must then lie in the ability of such schemes to address underlying market failures. When there are market failures such as externalities, the individual's consumption decision is very different from the

societal optimum. In the presence of externalities, the consumption decision of a single agent affects the welfare of others. By forcing individuals to consume 
more of a good than they would like, conditional cash transfer schemes serve to reconcile societal preferences with individual choices. This rationale makes eminent sense. Especially when addressing problems of human capital investment in children, externalities appear to be the norm rather than the exception. Children are unable to make their own human capital investment decisions and rely on their parents instead. Since the returns to education or health are typically felt in the long run while the benefits of, say, child labor are immediate, any difference in preferences between the child and the parents will lead to lower than socially optimal outcomes. In such cases, conditional cash transfers seek to restore efficiency in the economy.

The argument developed in this paper is that evidence of an externality, though compelling, may be insufficient grounds for conditional cash transfer schemes without additional information on its extent. This argument relies on the observation that such schemes have historically been used for an entirely different purpose, that of targeting resources and pro-poor redistribution. Specifically, when governments are unable to directly observe individual characteristics, conditional cash transfers induce self-selection so that the targeted group participates in the program and others opt out. A classic example is workfare. When cash is given only to people who work on a specific task, say road building, the rich usually opt out while the poor participate.

These two very different rationales for conditional transfers result in a tension. When used to increase investment in human capital, such schemes could have adverse redistributive impacts. Conversely, used as targeting or redistributive mechanisms, they could decrease efficiency. One way for policy-makers to then decide on the overall benefits would be to obtain information on both sides of the coin. How do efficiency gains compare to adverse redistributive impacts when conditional cash transfers are implemented? Similarly, when used for targeting purposes, how successful was the targeting given the associated efficiency loss?

This tradeoff is not new, either to researchers or to policy-makers. In fact, we find that a number of conditional cash transfer schemes used to increase efficiency explicitly attempt to minimize any negative redistributive impact by imposing further restrictions on who can and cannot get the money. These "eligibility" restrictions range from sophisticated requirements such as household income (Bolsa Escola in Brazil) to less demanding correlates of poverty such as land ownership or employment (Food for Education program in Bangladesh).

However, any such means testing requires additional expenditures and the careful collection of household data. As the popularity of these schemes increases and the emphasis shifts to "quick" results on important goals set by international donors, governments may be less willing to invest in such expensive efforts. In these cases, the tradeoff becomes starkly apparent. Careful analysis and 
information on the gains and losses is then critical for the overall evaluation of the program.

Figure 1 lays out the structure of the paper. Section 2 presents the textbook case of a conditional cash transfer, which shows that unconditional cash is better for individuals compared to cash with conditionalities. Given this result, rationales for conditionalities are based on their ability to address market failures or to target resources to a particular group. Sections 3 and 4 discuss each of these in turn. In each section, following the discussion of the rationale the paper turns to problems that have arisen in the use of such schemes in addressing their stated objectives.

The paper discusses two main concerns: low participation and fungibility. Low participation refers to the problem of program uptake. If individuals do not participate in the program, whether it was designed to increase human capital investment or to target resources, the program will not be successful. The problem of fungibility however, differs depending on the rationale. When used to increase efficiency, even with high program uptake the effects may be less than envisioned due to secondary impacts on the consumption of close substitutes. For efficiency to be enhanced, we require the conditioned-on good to not be fungible. When used as a targeting device, conditionalities actually come at the cost of efficiency. In this case, the more fungible the conditioned-on good, the lower the efficiency loss. The contrasting requirements on the fungibility of the good sets up a tradeoff between equity and efficiency. Section V hence goes beyond evaluations of these programs on the basis of their stated objectives and presents a framework for examining the overall costs and benefits of conditional cash transfers.

The use of conditional cash transfers to redistribute resources is well documented and therefore becomes a primary focus in this study only when discussing the tradeoff between equity and efficiency. Ravallion (2003) and Van de Walle (1998) present more general reviews of our experience with targeting and redistribution. The paper uses evidence from recent theoretical and empirical work to illustrate the issues discussed; a more extensive review is presented in the Appendix, Table 1.

\section{Conditional Cash Transfers: The Textbook Ex- ample and Rationales}

This paper views any scheme requiring a specified course of action in order to receive a benefit as a conditional cash transfer (henceforth CCT). The definition includes cash transfers based on human capital investments (such as schooling and health) but is sufficiently broad to encompass other schemes such as workfare programs (cash contingent on working in a program) or consumption transfers (cash for consuming certain medicinal supplements such as vitamins). 
Further, programs in which transfers are made in kind, or in which goods and commodities are made freely available to recipients for consumption are also accounted for in this definition. ${ }^{1}$

Figure 2 shows a CCT scheme given by the budget constraint AEDC: if the household consumes at least $X_{0}$, it receives an additional income given by ED. However, if the household consumes less than $X_{0}$ it does not receive an income transfer and remains on its pre-scheme budget constraint, AE. The figure also represents three types of households with different preferences, Type I (dotted), Type II (dashed) and Type III (solid). These three types of households exhibit very different behaviors: Type I does not use the scheme even when available and remains on the original section of her budget constraint, AE, consuming less than the required amount $X_{0}$. Type II is originally on the initial part of her budget constraint (consuming less than $X_{0}$ ) but shifts to consuming $X_{0}$ once the scheme becomes available. Finally, Type III was consuming more than $X_{0}$ before the scheme and continues to do so after its introduction.

This textbook example of individuals maximizing utility subject to a budget constraint suggests that CCTs are worse than distributing an equivalent amount in cash without the conditionality. In particular, for Type I and Type II households, the CCT is strictly worse than an equivalent amount given in cash, while for Type III households the CCT is exactly equivalent to unconditional cash grant. The central intuition is that CCTs, by their very nature, induce a distortion on the consumption choices of individuals: by forcing individuals to undertake some actions rather than letting them decide on their own, such schemes reduce their welfare compared to unconditional cash grants. The only individuals for whom CCTs and unconditional grants are equivalent are the ones who do not experience any distortion in their consumption decisions. In Figure 2, these correspond to the Type III households who were already consuming the minimum amount $X_{0}$ to start with.

This representation assumes that there are no market failures, so that decisions made by individuals are also optimal for the economy as a whole. When there are market failures however, CCTs play an important role in ensuring that individual decisions reflect both societal and individual preferences. Returning to the figure above, suppose that from a societal point of view, individuals of Type II under-invest in education: when they make their educational decisions, they do not take into account the effect of their own education on others around them. In this case, CCTs with conditionalities on education lead to a larger increase in social welfare than an unconditional cash grant. While this could reduce the welfare of the individual relative to an unconditional cash grant, it would make society as a whole better-off. This is the first rationale for CCTs: such schemes can be used to improve efficiency when there are underlying market failures in the economy.

\footnotetext{
${ }^{1}$ Matching grant programs, whereby loans are subsidized when borrowed for a specific investment purpose, are also included in the definition of CCT.
} 
A second rationale for CCTs relates to equity and redistribution. Suppose that instead of restoring the balance between societal preferences and individual decisions, the policy-maker is intrinsically interested in targeted transfers to the poor for redistributive purposes. ${ }^{2}$ The problem that the policy-maker faces is that when the poor are hard to identify and budgets are small, it is necessary to screen beneficiaries. When appropriately chosen, conditionalities can induce the desired target population to participate in the program while non-targeted individuals opt out. The idea behind successful screening is straightforward: if the benefits of the cash received exceed the cost induced by the conditionality for one group of the population but not for another, then only members of the first group will self-select into the program. In the figure, Type II and Type III self-select into the program while Type I opts out. Targeting is then the second rationale for CCTs: such schemes can be used as screening devices to target participants when individual characteristics are not easily observed.

These two rationales are thus very different. ${ }^{3}$ In the first case, the objective of the policy-maker is to increase the consumption of the conditioned-on good, whereas in the second, conditioning matters only insofar as it determines the identity of individuals who self-select into the program. The next two sections discuss these two rationales and the problems that have arisen in their use, Section 5 then returns to the tradeoffs between the two.

\section{$3 \quad$ Efficiency and Conditional Cash Transfers}

If the market outcome does not achieve the socially optimal allocation of resources, the use of CCTs can help alleviate such inefficiencies. What are the sources of externalities and how important are they? Further, what are the problems that CCTs face in achieving their stated objectives?

\subsection{Market Failures and the Use of Conditional Cash Trans- fers}

To examine the first question, the discussion below presents some examples from the recent literature. ${ }^{4}$ Although the papers reviewed here address a number of

\footnotetext{
${ }^{2}$ Inequality and poverty can also be considered as social concerns not internalized by the market, thus calling for government intervention.

${ }^{3} \mathrm{~A}$ third rationale for CCTs which has been often invoked is the presence of credit constraints or credit rationing. The theoretical justification in this case is yet unclear. Credit rationed individuals face a tighter static and/or dynamic budget constraint. As our discussion suggests, credit rationing is optimally alleviated with unconditional income transfers rather than CCTs; conditionality introduces an unnecessary distortion.

${ }^{4}$ The review presented here is not exhaustive. Some cases of market failures have been omitted from the review. In particular, moral hazard arguments, whereby aid is believed to induce a "laisser-aller" on the part of recipients is an important omission (see Ravallion, 2003). If aid is targeted to the poor, this might create an incentive to remain poor, inducing excess consumption. In this case, CCTs encourage investment instead of immediate consump-
} 
different concerns, they share a common theme. In each of these studies, an inefficiency arises due to the inability of individuals to reward or punish others based on a particular set of actions. This inability leads to a chasm between societal preferences and individual decisions; more efficient outcomes can then be achieved through the use of conditional transfers.

\subsubsection{Direct externalities}

When individual decisions have a direct effect on the rest of the society, there are externalities. Two such externalities that have received attention in the recent literature are physical externalities and learning externalities. Physical externalities arise in a number of contexts. For instance, Miguel and Kremer (2003a, 2003b) study a deworming project, where free deworming treatment was provided to rural primary school children in Kenya. They show that the deworming program resulted in positive health and school participation effects for those in the treatment as opposed to the control group (which received no treatment). Furthermore, they cite epidemiological theories, which suggest that "(...) medical treatment for helminth infections creates externality benefits for other community members by reducing worm deposition in the community and thus limiting re-infection among community members." These externalities are confirmed for the program: the deworming program had positive effects for untreated students in treatment schools and students in neighboring schools as well. The authors conclude that the size of the externality could be over 20 times as large as the cost of deworming. Starting with the premise that parents and children do not take into account the positive benefits on the whole community of their taking (and paying for) deworming pills, the overall consumption of deworming treatment is likely to be largely suboptimal. There consequently is a clear role for policy-makers to subsidize deworming treatment to restore efficiency. ${ }^{5}$

Learning externalities arise frequently in technology adoption scenarios. Significant benefits accrue once the attributes of a new technology are known to the community; nevertheless, learning about a new technology often involves costly experimentation. In this case individuals, who do not take into account the benefits that their early experimentation will have on the stock of knowledge in the community, may be unwilling to invest their time and effort leading to a "free-rider" problem: they will prefer to "wait and see" rather than experiment

tion. Another omitted argument (with little empirical evidence at the moment) is the case of bounded rationality. If individuals are unable to undertake appropriate investment decisions due to bounded rationality or behavioral problems such as hyperbolic discounting, then CCTs act as substitutes for individual decision-making; the government essentially behaves as a paternalistic agency (Basu, 2003 discusses this issue with regard to child labor). A third rationale relates to the political economy of aid and is addressed in the last section of the paper.

${ }^{5}$ However, the authors also state that “(..) it is difficult to draw conclusions about optimal deworming subsidies in the absence of a fully-fledged behavioral and epidemiological model." While positive externalities were large on average, it is hard to identify marginal externalities as they depend on how many others are being treated. 
with the new technology. As with the previous case, individual decision leads to under-investment in learning. There is considerable evidence to suggest that learning externalities play an important role in the path of technology adoption. For example, Foster and Rosenzweig (1995) find evidence that farmers are more likely to adopt a new technology when their neighbors do, but at the same time, are less likely to make the first move, preferring to wait until their neighbors first experiment.

\subsubsection{Household bargaining}

Market failures that can be remedied through conditional cash transfer schemes also arise when decisions are made through a bargaining process within the household. ${ }^{6}$ For example, recent contributions to the literature on child labor (Baland and Robinson 2000) have argued that the inefficiency of child labor and under investment in schooling arises due to a generic mismatch of parents' and children's preferences. If children could for instance commit to repaying parents for expenditure on their own education, education levels would be higher. However, since education decisions for the children are made by parents and children cannot commit to future repayments, parents typically favor positive short-run outcomes such as increased income due to child labor rather than long-term returns.

In an important body of work, Kochar (2000a) shows empirically that there is a significant difference between the parental and the child's rate of return to children's education and that parental rather than children's rates of return overwhelmingly determine the amount of education received. Similarly, educational levels in rural households respond strongly to labor market returns in urban areas (Kochar, 2000b). Taken together, Kochar's work suggests that rural families under-invest in education since they are unable to guarantee that their children will continue to reside in the village once they are educated: the inability of children to commit to such an action leads to the under provision of education. In such cases, conditional transfers schemes such as the Bolsa Escola, which provides cash only if the child attends school, increases efficiency by effectively addressing the difference between parental and child preferences. ${ }^{7}$

\footnotetext{
${ }^{6}$ For discussions of how baragaining in households affects decisions see Bourguignon and Chiappori (1994) or Basu (1999)

${ }^{7}$ Bargaining models also suggest that CCTs are not the only way in which under-investment in children can be addressed. An alternative may be to provide direct income support to members of the household whose preferences are more aligned with that of their children. For instance, it is often assumed that mothers allocate resources in a manner more consistent with their chidren's needs than fathers do. Empirically, this assumption has been tested by Lundberg and others (1997), who examine the change in the composition of household expenditures following a policy change in the child benefit scheme in UK in the late 1970s. Under the policy change, the universal child benefit, which had consisted primarily of a reduction in the amount of taxes the father had to pay, was replaced by a cash payment to the mother. This represented a substantial redistribution of income from husbands to wives (about 8 percent of average male earnings in the U.K. by 1980). The authors find a substantial increase in spending on children (and women), relative to men, and conclude that "(...) children do better when their mothers control a larger fraction of family resources".
} 


\subsection{Using Conditional Cash Transfers to Address Market Failures: Some Issues}

Even if we are convinced that there are important externalities and therefore CCTs are an appropriate solution, a number of problems may arise in the ability of the program to meet the stated objective of increasing, say, human capital investments. Two important problems relate to participation and fungibility.

\subsubsection{Low Participation}

The first condition for a CCT program to achieve its objective (and this is cross-cutting across schemes used to enhance efficiency or target resources) is that individuals participate. Thus, in programs with stipends for school attendance, the scheme should lead to an increase enrollment and attendance rates. Similarly, in workfare programs designed to target poor households, individuals should be willing to undertake the work required to receive the benefits.

Although the problem of participation is first-order in the sense that if there is low participation, the other problems are moot, conceptually it is entirely related to the size of the transfer and the cost of the conditionality. In Figure 2, Type I households did not participate in the program represented by the CCT of size DE. It is easily seen from the diagram that if the size of the transfer is increased (or the extent of the conditionality is decreased), households of Type I can be induced to participate as well: this is akin to a policy that rewards participants with large amounts if the conditionality is satisfied. Conversely, a decrease in the amount of cash transferred or a larger conditionality requirement, will eventually induce Type II individuals to drop out of the scheme. Low participation in CCT schemes are thus entirely due to a misalignment of the transfer and the conditionality. In the case of schooling for instance, the "cost" of the conditionality, which is the opportunity cost of a child at home may be too high compared to the cash benefits for households to send their children to school. $^{8}$

The importance of this problem is reflected in the large evaluation literature that examines program uptake. Four programs that the paper returns to in later sections all present careful results on program uptake. Bourguignon and others (2002) estimate the ex-ante impact of the Bolsa Escola in Brazil, a CCT scheme with the objective of increasing school enrollments and reducing child labor for children between the ages of 6-15 (transfers are given to children attending school at least $85 \%$ of the time). The ex-ante impact of the program on enrollment is large with a decrease in the percentage of children not enrolled from 5.8 percent to 3.9 percent, with stronger effects among the poor (9.1 percent to 4.7

\footnotetext{
${ }^{8}$ Note however that the small size of the transfer can arise either by design (policy-makers are unsure of the right size of transfer) or due to poor governance. While few studies have evaluated the latter, in a slightly different context studies by Ablo and Reinikka (2000) and Das and others (2003) suggest that there are large differerences between executed program budgets and the amount that actually reaches beneficiaries
} 
percent). These results are partially confirmed in an ex-post evaluation of the same program (Cardoso and Souza, 2003).

In Bangladesh, two important programs to increase school enrollment, the Food-For-Education and the Female Stipend Program, both resulted in increases in enrollment. As with the Bolsa Escola, both programs conditioned benefits, food in the first and cash in the second, on school attendance. The effects were significant and large. For the first program, Ravallion and Wodon (1999) show that an extra 100 kilos of rice increased the probability of school enrollment by over 0.15 for both girls and boys. For the second, Khandker and others (2003) estimate that an additional year of participation in the school stipend program leads to a 8 percent increase in girls' enrollment.

These three programs used CCTs to address under-investment in human capital. A program that was used to target resources that is discussed in some detail below was the Plan Jefes y Jefas in Argentina, whereby unemployed individuals were given cash benefits as long as they satisfied two conditionalities (discussed below). Galasso and Ravallion (2003) find that the conditionalities were not too severe, so that program uptake was high; in fact, the problem was that the uptake was "too high", and we return to this below.

\subsubsection{The Fungibility Problem}

The second problem that CCT schemes face relate to the fungibility of the conditioned-on commodity. The fundamental premise of a conditionality is the distortion of choices from the individual's optimal. However, this very logic creates an automatic incentive for individuals to try and offset the loss of individual utility that the conditionality imposes. The ability of individuals to offset any distortion imposed by the CCT program is the problem of fungibility. Fungibility usually arises when there is a close substitute for the conditioned-on commodity (which could be the commodity itself). In this case, the recipient can offset the distortion imposed by the conditionality if she appropriately decreases the consumption of or investment in the substitute, so that overall amounts are unchanged following the scheme even when the conditionality is satisfied. ${ }^{9}$

To see how the fungibility problem affects the ability of the program to achieve its objectives, consider the Type III individuals in Figure 2. Since this group was already consuming the necessary amount of the good, the increase in the commodity following the scheme is no more than that under an unconditional income grant; for this particular group, the commodity is perfectly fungible. In less extreme cases, such substitution may take the form of decreasing the consumption of a close substitute (eating less spinach when given iron

\footnotetext{
${ }^{9}$ When households can access a second-hand market where the conditioned-on good can be sold, there is a first-order problem of fungibility. Making sure that such instance does not occur is a prerequisite for "conditionality" to make any sense; while this is important, the paper assumes that this problem is well known and dealt with to the best of the policy-makers ability.
} 
tablets), changing patterns of consumption (eating less at home when given food in school) or even reallocating investments in human capital (sending fewer boys to schools when girls are given a stipend) within the household.

How can one evaluate whether fungibility is a problem? There are two approaches in the literature. One approach is to try and directly estimate the impact of the program on close substitutes of the conditioned-on good. Thus in the case where iron tablets are given, one could estimate the impact of providing the tablets on iron intake in daily food. A second approach is to examine a variable that depends both on the conditioned-on good as well as the substitutes. Hemoglobin in the blood supply depends both on the amount of iron taken through tablets as well as the consumption at home. If, as a consequence of providing iron tablets there is an increase in hemoglobin levels, it must be the case that the overall intake of iron has increased. ${ }^{10}$

Both methods have advantages and drawbacks. With the first method, direct estimates of the extent of substitution can be obtained (how much did iron consumption decreased at home?) while with the second, we can only tell whether substitution was one-for-one or not. At the same time, the first method requires very clear knowledge of what the substitutes actually are. For iron tablets the substitutes are straightforward, but this is not true for other programs. A mother may substitute for better health care in the clinic in a number of ways (washing hands, boiling water etc.) which may be difficult to list, let alone measure. By concentrating on outcomes, such as child height, that depend both on the health care in the clinic as well as health care at home, the "reduced-form" impact of the program can be estimated.

Jacoby (2002), is one of the few papers that provide a direct estimate of substitution. In a feeding program in the Philippines, extra calories provided in school were not substituted away by the household. Close to 80 percent of the calories provided through the program resulted in an absolute increase in total caloric intake. This paper is based on the idea that households smooth consumption so that ideally daily caloric consumption should be the same. By comparing the caloric consumption of children on school and non-school days, Jacoby shows that households do not substitute away calories from the program. On school days, the caloric intake of children is higher by 80 percent of the caloric value of the feeding program.

In contrast, two papers that use the second approach are Behrman and Hoddinott's (2001) evaluation of PROGRESA in Mexico, and Stifel and Alderman's (2003) analysis of Vaso de Leche in Peru. Behrman and Hoddinott (2001) evaluate a CCT scheme aimed at improving child nutrition and health. Under this program, eligible mothers had to visit clinics regularly and participate in growth monitoring to receive nutritional supplements and the cash transfers.

\footnotetext{
${ }^{10}$ See Thomas and others (2003) for preliminary results of an iron-supplement-based nutrition program in Indonesia.
} 
They study the effect of PROGRESA's pre-school child nutrition programs on child height and report that the programs had substantial positive impacts on growth and in reducing the probability of being stunted for children aged 13 . The authors also postulate that the program addresses externalities arising from household bargaining: PROGRESA directs its resources to mothers based in part on prior evidence from other populations that suggest better child health and nutrition when women rather than men receive resources. ${ }^{11}$

A natural question is whether fungibility is an issue in all CCT schemes or only particular types such as nutritional interventions. For instance, if a CCT scheme leads to higher school enrollment, is there an associated fungibility problem? Although there is limited empirical evidence, the answer is yes. In particular, these programs may reduce the amount of education that is given at home to the child or the composition of education across children. In the Female Stipend Program in Bangladesh, Khandker and others (2003) examine whether providing stipends only for girls had an effect on boys' schooling since the program effectively reduces the price of girls' compared to boys' education. Their evidence is mixed. Using household data they find that the effect on boys' schooling is statistically insignificant. However, using school enrollment data they find a 29 percent decline in boys' enrollment in program schools. This can either be interpreted as an absolute decline, or, given the evidence from household surveys, a movement away from program to non-program schools for boys, although why this should happen is not clear.

\section{Equity and Conditional Cash Transfers}

The second objective of conditional cash transfers, as a screening mechanism for targeting and redistribution, has a long history in workfare and food distribution programs. Recent reviews by Ravallion (2003) and Van de Walle (1998) document both the ways in which these schemes have been evaluated as well as their ability to lift households out of poverty. These reviews show that success is closely tied to whether the conditionality simultaneously satisfied two goals: ensuring that the targeted group was willing to satisfy the conditions of program participation and ensuring that the group not targeted found the conditionality too expensive compared to the rewards of the program. In the targeting literature, the failure of the first is often referred to as "errors of exclusion" and

\footnotetext{
${ }^{11}$ In Vaso de Leche, a program that Stifel and Alderman (2003) consider to be the largest social transfer in Peru, selected households receive milk or milk-products. Although the program is well targeted to the poor and leakages are minimal, it fails to achieve its main nutritional objective of improving child height. The authors argue that the reason behind the lack of impact is that half the in-kind transfers are infra-marginal (Type III agents in Figure 1) so that the provision of milk did not have an impact beyond the income transfers it represented. The authors conclude that cash transfers may have been a superior means of increasing consumption of milk if they are less costly and more efficiently distributed than food transfers. However, as suggested by Van de Walle (1998), in-kind transfers might be more politically feasible than cash transfers. Whether political gains outweigh implementation cost in this instance remains an open question.
} 
the latter as "errors of inclusion". Errors of either type increase the cost of the program (by distributing resources to individuals not in the target group) and may also reduce benefits to the targeted population. ${ }^{12}$

\subsection{Means Testing}

Given the stringent requirements for CCT programs to be successful as screening mechanisms, one approach, means-testing, has been to avoid the problem entirely by directly collecting more data on the identity of individuals. Innovative options have emerged during the last decade with different eligibility criteria. In some programs (such as PROGRESA in Mexico or Bolsa Escola in Brazil) means tests are based on detailed data collection and identification of household wealth. The Bolsa Escola, for instance, provides cash only to households with per capita monthly incomes less than 90 reais. In other cases, where data collection on household assets may be too expensive or politically infeasible, imaginative indicators of wealth have been used. Two such examples are the food-for-education program in Bangladesh and the Vaso de Leche program in Peru.

Under the food for education program in Bangladesh, food was provided to children attending at least 85 percent of classes in school. In addition, an attempt was also made to ensure that only poor households were eligible for the transfer. In the absence of data on household income or assets, the eligibility criteria were based on ostensible correlates of poverty - whether or not the household head is a widow, the amount of land owned by the household and the employment of the household head. These criteria did ensure that the poor received higher transfers, but not by much. Galasso and Ravallion (2004) show that the difference in receipts between the rich and the poor was marginal. For a "targeting-differential" coefficient defined to be -1 if the program benefits accrued only to the rich and +1 if they accrued only to the poor, the program coefficient was +0.13 .

The Vaso de Leche program in Peru faced similar problems in identifying poor households. In this case, a committee was in charge of "observing" the relevant characteristics of households to determine eligibility and despite the potential ambiguities of such as strategy, the program resulted in greater transfers to the poor. Using measures of participation and expenditure levels, Stifel and Alderman (2003) show that the Vaso de Leche program resulted in the allocation of more than 60 percent of the value of all transfers to the poor.

Thus, when means testing is feasible the problem of targeting resources to a particular subset of households is reduced. The extent to which this becomes less of a problem depends on the sophistication of the data - in cases such as

\footnotetext{
${ }^{12}$ Either because some targeted individuals will be unable to enroll due to overcrowding, or because of general equilibrium effects in the economy.
} 
the Bolsa Escola, where the means test is based on detailed household information, targeting is more efficient than in the Food for Education program, where targeting was not much better than a random distribution of resources to the rich and poor.

\subsection{Screening}

In cases where means tests are logistically or politically infeasible, CCTs can be used as screening mechanisms. For screening to work, the net benefit of the scheme which is the benefit from the cash transfer net of the opportunity cost of satisfying the conditionality, must be positive for the targeted group while negative for others. If this asymmetry is satisfied, then only members of the targeted group self-select into the program. ${ }^{13}$ An example of particular interest, which we return to below due to its wide use and applicability, is that of targeting the poor. In such cases, the requirements for self-selection can be expressed in terms of the income effect of the conditioned-on good so that targeting is successful if the conditioned-on good is inferior. ${ }^{14}$ Then, the rich (who consume less of the good to start with) will find the costs of meeting the conditionality higher than the poor and will disproportionately opt out of the program.

In Figure 2, the conditionality $X_{0}$ induces exactly this sort of screening. Type II and Type III individuals participate in the program, while Type I individuals voluntarily decide to opt out. If we are to think of this as targeting to the poor, Type II and Type III individuals are less wealthy and Type I individuals are more wealthy. The good is inferior because consumption decreases in wealth. Examples of CCTs as screening mechanisms include the well-documented workfare programs (Van de Walle, 1998, Galasso and Ravallion, 2003), rationing of food or health subsidies by queueing (Alderman, 1987) and the packaging of commodities that are unappealing to the rich (Alderman and Lindert, 1998, Jacoby 1997). Nevertheless, the requirements for CCTs as screening mechanisms may be hard to satisfy.

The Plan Jefes y Jefas program in Argentina was designed to increase employment by providing a subsidy for individuals trying to find employment. Household heads who were initially unemployed could apply for the program under which they would receive cash if they found employment and undertook "20 hours of counterpart activities such as basic community work, training activities, school attendance or employment in a private company with a wage subsidy for six months" (Galasso and Ravallion, 2003). Why was the conditionality of counterpart activities imposed?

\footnotetext{
${ }^{13}$ This "single-crossing condition" requirement is detailed in Spence (1973), and Rothschild and Stiglitz (1976).

${ }^{14}$ The consumption of an inferior good decreases with wealth. In contrast, the consumption of a normal good increases with wealth.
} 
In Argentina it is hard to verify whether an individual is unemployed or not, since over half of all employment is in the informal sector. The 20-hour requirement acts as a screening device: individuals who are already employed are unwilling to sacrifice their work (or leisure) time for the benefits of the program, whereas this cost is much lower for those who are currently unemployed. The conditionality was only partially successful in ensuring that the already employed did not participate and even less so in increasing employment. In particular, Galasso and Ravallion (2003) find that only 3 percent of beneficiaries had formal employment to start with and so the program did ensure that those with formal employment did not participate, but they also find that 19 percent of beneficiaries were employed in the informal sector to start with.

At the same time, increases in employment rates were much less than envisaged due to the inability of the program to distinguish between individuals who were "inactive", i.e. out of the labor force, and those who were unemployed, that is people actively searching for a job but unable to find one. In fact, 38 percent of eventual recipients were inactive and consequently Galasso and Ravallion (2003) conclude that "a large share of the participants were women who would not otherwise have been in the labor force". The conditionality thus failed on two counts: it was not "expensive" enough to ensure that individuals employed in the informal sector opted out, and it was not "expensive" enough compared to the opportunity cost of losing 20 hours of housework. This illustrates the idea that program uptake can also be too high, as discussed earlier in the paper.

What makes the Plan Jefes y Jefas program particularly interesting is that it was successful in ensuring that program benefits went primarily to the poor, even though poverty alleviation was not a primary focus of the program. Galasso and Ravallion (2003) find that the enforcement of eligibility criteria and counterpart activities as conditionalities implied that 90 percent of the participants were below the official poverty line. Indeed, 20 hours of community work is an inferior good in this context. Community work is likely to be more expensive in terms of foregone income and leisure for the rich than for the poor and this naturally induces self-selection of the poor into the program.

The program thus demonstrates both the pitfalls and the sometimes unforeseen benefits of using CCTs as screening devices. To the extent that the conditionality does not reflect the differential opportunity costs of the targeted and the non-targeted groups, it will not meet the stated objectives. At the same time evaluations that examine the entire effect of the program instead of one particular component yield critical information for future programs. Clearly, the requirement of 20 hours of community work can be used to separate poor and rich individuals for targeted poverty alleviation efforts. 


\section{Conditional Cash Transfer Schemes and the Efficiency-Equity Debate}

Are these two very different rationales for CCTs compatible? The preceding discussion on the role of fungibility when CCTs are used to improve efficiency and when they are used as screening devices suggests that there may be a tension between the two. Using CCTs to increase human capital investments could impact adversely on equity; similarly, the distortions required for self-selection to work could impose an efficiency cost. Policy makers seem to be aware of the contradictory roles that CCTs are sometimes required to fulfill. The use of eligibility criteria and means-tests in programs such as the Bolsa Escola and the PROGRESA are specifically introduced to minimize adverse redistributive impacts. In other cases, the net impact of the tradeoff is less clear.

\subsection{Efficient but not equitable?}

The primary motivation behind the Female Stipend Program in Bangladesh discussed previously was to increase secondary school enrollment of girls. Different rates of return to education for parents and children provide a justification based on externalities for this program. A CCT, that gives stipends to girls who attend at least 85 percent of classes addresses this externality and aims to increase the investment in human capital. What differentiates this program from the Food-for-Education program is the complete lack of means-testing; besides the attendance requirement, there are no further eligibility criteria.

Khandker and others (2003) evaluate the program and find that girls' secondary education increased substantially as a result. If girls' education levels were inefficiently low to begin with, the program served to decrease the gap between societal preferences and individual actions. However, in Bangladesh secondary public schooling for girls is a normal good with richer households more likely to enrol their children in secondary schools compared to the poor. For particularly poor households, it is likely that the opportunity cost of 85 percent attendance in terms of labor lost exceeds the benefit of the stipend. Consequently Khandker and others (2003) do find that the program has adverse distributional impacts: "(The) currently un-targeted stipend disproportionately effects the school enrollments of girls from households with larger land wealth. Targeting towards the land poor may reduce the overall enrollment gains of the program while equalizing enrollment effects across landholding classes."

Note that the adverse redistributive impact is not a sufficient reason to discontinue the program. One approach to address this problem, as suggested by Khandker and others (2003) is to introduce means-tests. What if meanstests are not feasible? In this case, to decide whether the program provides net benefits, one has to evaluate the size of the efficiency gain and compare this to the loss from ineffective targeting. This efficiency gain is not the 8 percent gain in girl enrollment, but the size of the externality that the program corrects for. 
The deworming program in Kenya (Miguel and Kremer, 2003a) provides an example of the difference between program participation and efficiency gains. Under this program, there was a large increase in the attendance of treated children - this is exactly equivalent to the 8 percent gain in the Female Stipend Program. The efficiency gain though is different. Estimating the size of the externality, Miguel and Kremer suggest that the net externality is 20 times as large as the direct effect and thus there are large gains in efficiency. Although they do not study the distributional impact of the program, these large efficiency gains are unlikely to be outweighed by poor targeting, especially given the cost of deworming in the region.

\subsection{Equitable but not efficient?}

Using CCTs as a screening device for targeting also comes at a cost. Such cost can either be due to the distortion in consumption and investment choices induced by the conditionality, or the "laisser-aller" that continuing aid flows may create. For the latter, Ravallion (2003) however finds that empirical evidence in support of such a phenomenon is extremely limited: in poor countries, the problem is usually one of under rather than over-insurance.

One example of the former is that of targeted food subsidies to the poor, where the quality of the food given is low. Since low quality food is an inferior good (as income increases, people start increasing the quality of the food they eat) this would presumably lead to greater food subsidies for the poor compared to the rich. The Nutribun and Milk program in Jamaica is one such example. Under this program, children in school received a nutritious baked product everyday. Presumably, what made the Nutribun inferior was the monotony of the program. In his evaluation, Jacoby (1997) finds that the program achieved its aims in terms of targeting - lower uptake among the rich implied that the benefits from the program as a share of total consumption fell from 4.8 percent for the first decile to 1.2 percent for the fifth decile.

The effective targeting did not necessarily make for a successful program. Jacoby (1997) argues that the deadweight loss of the program was large. By using the notion of equivalent variation - the smallest increment in cash that would have achieved the same objective - Jacoby (1997) shows that the benefit per respondent was $\mathrm{J} \$ 152$, compared to the program cost of $\mathrm{J} \$ 400$. Thus more than half of the costs of the program were estimated deadweight losses due to the implied conditionality of the transfer. Whether the benefits of targeting exceeded the deadweight loss of the program is then an important issue for policy-makers.

A similar question arises in the Plan Jefes y Jefas program discussed above. Although the program did result in greater benefits to the poor, what was the efficiency cost in terms of foregone incomes from the conditionality (the 20hour counterpart work requirement)? Galasso and Ravallion (2003) estimate 
the average opportunity cost to be around 50 pesos, corresponding to a third of the amount of cash transferred by the scheme itself. A possible next step would be to trace out the losses in targeting effectiveness from decreasing the conditionality against the gains from increasing efficiency.

\subsection{Both equitable and efficient?}

The tradeoff between equity and efficiency need not arise in all cases. One way in which this tradeoff has been addressed is through imposing additional eligibility criteria when CCT schemes are used to increase efficiency. Even if eligibility criteria are not available, theoretically it may be possible for conditionalities to serve the dual objectives of equity and efficiency (Besley and Coate, 1992). The idea behind this argument relies on the segmentation of the market into two, one that is used primarily by the rich and the other by the poor. Important examples of such segmented markets occur frequently in health and education, particularly in low income countries. When there is both a private and a public sector, the rich tend to overwhelmingly use private schools (and health clinics) while the poor use the public system (Alderman and others, 1996, Mahal and others, 2001). Hence, providing cash only to the public system could effectively target the poor. At the same time, if we believe that human capital investments in children are generically plagued by externalities, increasing education levels and the health status of children will address an existing market failure. Taken together, conditional cash transfer schemes that condition cash on (a) attendance in schools in the public sector (for education) and/or (b) child visits to government health centers (for health) could satisfy both equity and efficiency rationales simultaneously.

Unfortunately, we have been unable to find much evidence for this mechanism. The only program discussed in the literature that imposes a conditionality without some sort of means test is the Female Stipend Program in Bangladesh. The results from this program, while encouraging on the efficiency front, have been poor in terms of equity. One explanation could be the lack of available opportunities - if there are few private schools in rural Bangladesh, then the market segmentation assumption is incorrect. Another view point is that the reason why there are so few programs that do not have a means test in addition to the conditionality is because policy-makers realize that the twin goals of equity and efficiency are hard to satisfy simultaneously and means testing are relatively effective and inexpensive tools to achieve targeting, compared to other screening devices.

\subsection{Beyond Efficiency: The Political Economy of Aid}

The two rationales discussed in this paper form the basis for a number of conditional cash transfer schemes, but are by no means an exhaustive list. A third important consideration relates to the incentives of the institutions that provide the cash for such schemes, particularly when they are not country governments. 
These programs serve the direct purpose of imposing donor preferences when tastes over allocations differ (Culyer 1991 and Tobin 1970). Yet, without necessarily assuming different preferences, an agency view of policy making can provide a rationale for why CCTs are desirable and increasingly popular. Since aid agencies are accountable to donors and ultimately taxpayers, transparent and observable measures of performance need to be implemented to ensure proper monitoring. CCT schemes are then suitable tools for aid agencies to move toward the announced objectives, although the exclusive focus on measurable dimensions of performance may come at the expense of more comprehensive and efficient development policies, the impacts of which are difficult to assess. ${ }^{15}$

To illustrate this, consider the Millennium Development Goals (MDGs) for education: "Ensure that, by 2015, children everywhere, boys and girls alike, will be able to complete a full course of primary training" (http://www.development goals.org/Education.htm). This objective includes enrollment of all school-age children and universal primary completion. What is interesting is that the enrollment rate is offically included in the MDG indicators, but the primary completion rate is not. The former is a clearly identifiable indicator, the latter is fuzzy with differing definitions and scales across countries. The problem again arises due to an externality - in making their schooling decisions, it is unlikely that parents take into account the idea that enrollment might induce additional aid flows from donor countries. Imposing conditionalities then yields considerable political gains in the production of verifiable and clearly observable outcomes.

Nevertheless, the stress on verifiability may come at a cost. The first round of CCT programs that were implemented, including the Bolsa Escola and the Food for Education, were careful in their consideration of the tradeoffs between equity and efficiency. Programs such as the Female Stipend in Bangladesh were not. Unfortunately, the MDGs for education do not require that adverse distributional impacts of educational policies are minimized and hence the temptation to implement programs that perform better on the verifiable dimension only may be high. This may lead, on the one hand, to CCT schemes that enhance efficiency but worsen equity and on the other, to schemes that yield immediate gains but impose long-run costs.

Continuing with education, Case and Deaton (1999) find for South Africa that pupil-teacher ratios have strong and significant impacts on enrollment, educational achievement and test scores for numeracy. Should South Africa then use the mainstream CCT programs to improve educational outcomes? While these programs will arguably have immediate impacts, the alternative of reducing class sizes could have long-lasting positive effects, which is hard to measure in the short run. These two alternative policy instruments illustrate the tradeoff between short-term and long-term impacts. These results also suggest a

\footnotetext{
${ }^{15}$ For a formal treatment of this problem, see Holmström and Milgrom (1991).
} 
quantity-quality tradeoff: increasing enrollment (through the implementation of CCT schemes for example) without supplying additional teachers will be harmful to educational achievements and test scores in the long run. While emphasis on "demand-side" policies (such as CCTs) brings political gains and ultimately future aid flows, it comes at the expense of other policy instruments and these tradeoffs require careful consideration.

\section{Conclusion}

This paper examines a wide range of CCT programs and applies an analytical lens to understand and interpret various evaluations in the literature. Two important ideas emerge. First, the use of CCT schemes can be justified on efficiency grounds to alleviate market failures, and/or on equity grounds to redistribute resources. The choice of the good on which the conditionality is imposed is crucial. In particular, the extent to which the good is fungible makes a significant difference, depending on the underlying motivation for the program. Second, these two motivations while theoretically distinct, are simultaneously present in a number of different CCT programs. This tension between efficiency and equity can be addressed through the conditionality requirement, the amount of the cash conditionally transfered, and the refinement and enforcement of eligibility criteria.

The paper uses the theoretical and empirical literature to illustrate the rationale, the problems and the tradeoffs inherent in conditional cash transfer programs. While researchers have typically addressed these issues separately, policy-makers need to incorporate a number of different factors in a comprehensive framework to design optimal schemes. A future research agenda would then call for a synthesis across papers that provide a holistic view of these programs.

\section{References}

[1] Ablo, Emmanuel and Ritva Reinikka, "Do Budgets Really Matter: Evidence from Public Spending on Education and Health in Uganda". World Bank Policy Research Working Paper No. 1926. 2000.

[2] Alaii, Jane A. and others, "Perception of Bed Nets and Malaria Prevention Before and After a Randomized Controlled Trial of Permethrin-treated Bed Nets in Western Kenya". The American Society of Tropical Medicine and Hygiene, 68(4), 142-48. 2003.

[3] Alderman, Harold, "Allocation of goods through non-price mechanisms: evidence on distribution by willingness to wait". Journal of Development Economics, 25:105-124. 1987

[4] Alderman, Harold, Peter F. Orazem, and Elizabeth M. Paterno, "School Quality, School Cost, and the Public/Private School Choices of Low-Income 
Households in Pakistan". World Bank Working Paper Series on Impact Evaluation of Education Reforms No. 2. December 1996.

[5] Baland, Jean-Marie, and James A. Robinson, "Is Child Labour Inefficient?". The Journal of Political Economy 108(4), 663-679. August 2000.

[6] Basu, Kaushik, "Child Labor: Cause, Consequence, and Cure, with Remarks on International Labor Standards". Journal of Economic Literature 37(3), 1083-1119. September 1999.

[7] Basu, Kaushik, "Global Labour Standards versus Freedom of Choice". WIDER Annual Lecture. 2003

[8] Behrman, Jere R., and John Hoddinott, "Program Evaluation with Unobserved Heterogeneity, Selective Implementation, and Imperfectly Targeted Beneficiaries: The Mexican PROGRESA Impact on Child Nutrition". Unpublished manuscript. August 2001.

[9] Besley, Timothy, and Stephen Coate, "Public Provision of Private Goods and the Redistribution of Income." The American Economic Review 81(4), 979-984. September 1991.

[10] Bourguignon, Francois, and Pierre-André Chiappori, "The Collective Approach to Household Behavior". in The Measure of Household Welfare, Richard Blundell, Ian Preston, and Ian Walker, eds. Cambridge, UK: Cambridge University Press. 1994.

[11] Bourguignon, Francois, Francisco H.G. Ferreira, and Phillippe G. Leite, "Ex-ante Evaluation of Conditional Cash Transfer Programs. The Case of Bolsa Escola". World Bank Policy Research Working Paper No. 2916. October 2002.

[12] Cardoso, Eliana and André P. Souza, "The Impact of Cash Transfers on Child Labor and School Attendance in Brazil". mimeo. November 2003.

[13] Case, Anne, and Angus Deaton, "School Inputs and Educational Outcomes in South Africa". The Quarterly Journal of Economics, 114(3), 1047-84. August 1999.

[14] Culyer, A. J., "The Political Economy of Social Policy". Aldershot, Gregg Revivals. 1991.

[15] Das, Jishnu, Stefan Dercon, James Habyarimana and Pramila. Krishnan, "Rules vs. Discretion: Public and Private Funding in Zambian Education". Mimeo The World Bank. 2003.

[16] Foster, Andrew.D., and Mark R. Rosenzweig, "Learning by Doing and Learning from Others: Human Capital and Technical Change in Agriculture". The Journal of Political Economy 103(6), 1176-1209. December 1995. 
[17] Galasso, Emanuela and Martin Ravallion, "Social Protection in a Crisis: Argentina's Plan Jefes y Jefas". World Bank Policy Research Working Paper No. 3165. November 2003.

[18] Galasso, Emanuela and Martin Ravallion, "Decentralized Targeting of an Anti-Poverty Program". Journal of Public Economics. Forthcoming 2004

[19] Holmström, Bengt R. and Paul Milgrom, "Multi-Task Principal-Agent Problems: Incentive Contracts, Asset Ownership and Job Design". Journal of Law, Economics and Organization, 7. 1991.

[20] Jacoby, Hanan G., "Self-Selection and the Redistributive Impact of In-Kind Transfers." The Journal of Human Resources 32(2), 233-249. Spring 1997.

[21] Jacoby, Hanan G., "Is there an Intrahousehold 'Flypaper Effect'? Evidence from a School Feeding Programme." The Economic Journal 112, 196-221. January 2002.

[22] Khandker, Shahidur R., Mark M. Pitt, and Nobuhiko Fuwa, "Subsidy to Promote Girls' Secondary Education: The Female Stipend Program in Bangladesh". Mimeo. March 2003.

[23] Kochar, Anjini, "Institutional Deterrents to the Spread of Schooling". Mimeo Stanford University. July 2000.

[24] Kochar, Anjini, "Migration and Schooling Rates of Return". Mimeo Stanford University. August 2000.

[25] Lundberg, Shelly J., Robert A. Pollack, and Terence J. Wales, "Do Husbands and Wives Pool Their Resources. Evidence from the United Kingdom Child Benefit". The Journal of Human Resources 32(3), 463-480. Summer 1997.

[26] Mahal, Ajay, Abdo S. Yazbeck, David H. Peeters, and G.N.V. Ramana, "The Poor and Health Service Use in India". Mimeo. March 2001.

[27] Miguel, Edward, and Michael Kremer, "Social Networks and Learning about Health in Kenya". Mimeo. July 2003.

[28] Miguel, Edward, and Michael Kremer, "Worms: Identifying Impacts on Education and Health in the Presence of Treatment Externalities". Forthcoming Econometrica. 2003.

[29] Nahlen, L. Bernhard, John Paul Clark, and David Alnwick, "InsecticideTreated Bed-Nets". Supplement to The American Journal of Tropical Hygiene and Medicine, 68(4). 2003.

[30] Ravallion, Martin, "Targeted Transfers in Poor Countries. Revisiting the Tradeoffs and Policy Options." World Bank Policy Research Working Paper No. 3048. May 2003. 
[31] Ravallion, Martin, and Quentin Wodon, "Does Child Labor Displace Schooling? Evidence on Behavioral Responses to an Enrollment Subsidy". World Bank Policy Research Working Paper No. 2116. May 1999.

[32] Rawlings, Laura.B., and Gloria M. Rubio, "Evaluating the Impact of Conditional Cash Transfer Programs: Lessons from Latin America". Unpublished manuscript. June 2003.

[33] Rothschild, Michael, and Joseph E. Stiglitz, "Equilibrium in competitive insurance markets: An essay in the economics of imperfect information". The Quarterly Journal of Economics, 90(4), 629-49. November 1976.

[34] Schultz, T. Paul, "School Subsidies for the Poor: Evaluating the Mexican Progresa Poverty Program". Center Discussion Paper 834. Yale University. August 2001.

[35] Spence, A.Michael, "Job market signalling". The Quarterly Journal of Economics 87(3), 355-74. August 1973.

[36] Stifel, David, and Harold Alderman, "The "Glass of Milk" Subsidy Program and Malnutrition in Peru". World Bank Policy Research Working Paper No. 3089. June 2003.

[37] Thomas, Duncan, and others, "Iron deficiency and the well-being of older adults: Early results from a randomized nutrition intervention", Mimeo. November 2003.

[38] Tobin, James, "On Limiting the Domain of Inequality". Journal of Law and Economics 13(2), 263-77. 1970.

[39] Van de Walle, Dominique, "Targeting Revisited." World Bank Research Observer, 13(2), 231-248. August 1998. 


\section{Figure 1: Flow Chart}

Textbook Case: Unconditional transfers are better than conditional transfers

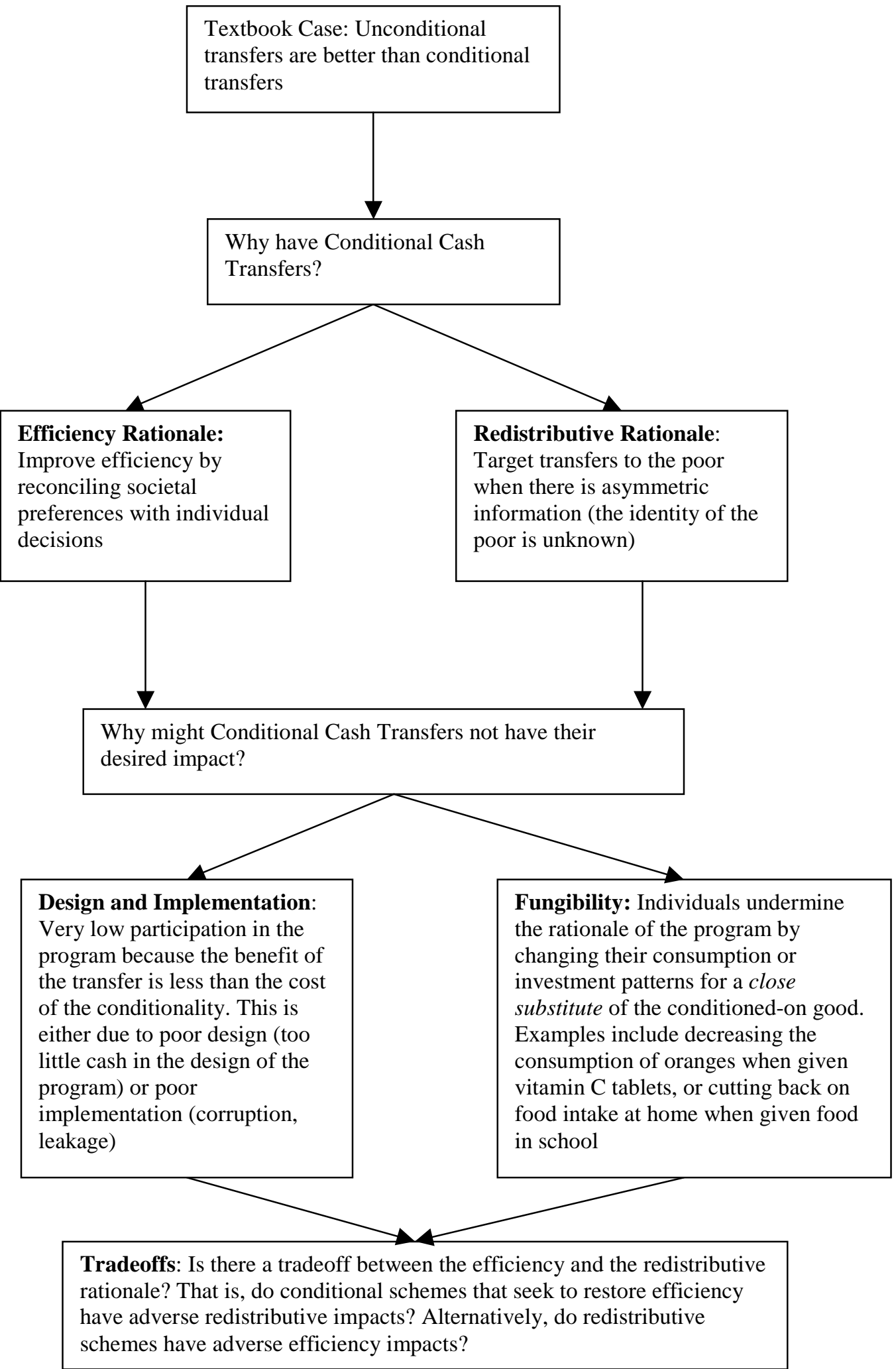

Cost-Benefit Analysis: How big are the externalities that the conditional cash transfer addressed in the first place? 
Figure 2: Households and Conditional Cash Transfer Schemes

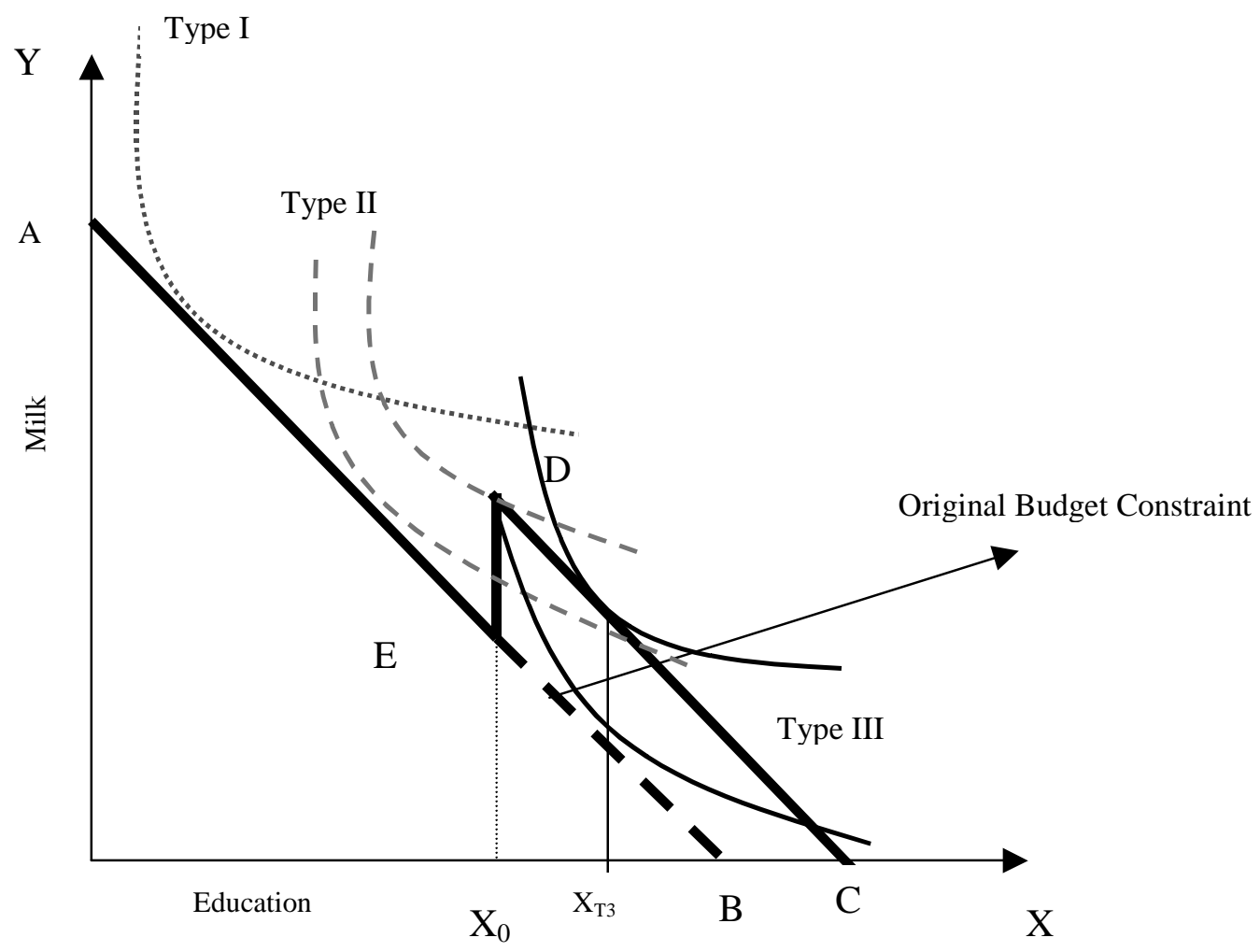


Table 1: Selected Evaluations of Conditional Cash Transfers

\begin{tabular}{|c|c|c|c|}
\hline Authors & Program & Main Finding & Issues Covered \\
\hline $\begin{array}{l}\text { Alaii and others } \\
\text { (2003) }\end{array}$ & $\begin{array}{l}\text { The western Kenya } \\
\text { insecticide-treated } \\
\text { bed net trial (ITN) }\end{array}$ & $\begin{array}{l}\text { - Perceived private benefits from ITN use is } \\
\text { low. } \\
\text { However, positive externalities imply that } \\
\text { ITN had an effect on the spatial } \\
\text { distribution of malaria vectors within } 600 \\
\text { meters of the control villages. } \\
\text { Effect on child mortality, moderate } \\
\text { anemia, high-density parasitemia, and } \\
\text { hemoglobin levels within } 300 \text { meters of } \\
\text { the control villages. }\end{array}$ & $\begin{array}{l}\text { Implementation, physical } \\
\text { externalities }\end{array}$ \\
\hline $\begin{array}{l}\text { Alderman and } \\
\text { Lindert (1998) }\end{array}$ & $\begin{array}{l}\text { Food subsidies } \\
\text { (Tunisia) }\end{array}$ & $\begin{array}{l}\text { Self-targeting through choice of } \\
\text { commodity found to be effective to } \\
\text { improve targeting efficiency. } \\
\text { However, this effect is not as sharp as } \\
\text { other mechanisms employed elsewere, } \\
\text { such as means-tested food stamps in } \\
\text { Jamaica and geographically targeted food } \\
\text { supplementation in Peru. }\end{array}$ & $\begin{array}{l}\text { Targeting, redistribution, political } \\
\text { economy of aid. }\end{array}$ \\
\hline $\begin{array}{l}\text { Behrman and } \\
\text { Hoddinott (2001) }\end{array}$ & $\begin{array}{l}\text { PROGRESA } \\
\text { (Mexico) }\end{array}$ & $\begin{array}{l}\text { Positive impact of nutritional supplements } \\
\text { and other child health interventions on } \\
\text { child growth and probability of being } \\
\text { stunted. }\end{array}$ & Household bargaining, fungibility \\
\hline
\end{tabular}




\begin{tabular}{|c|c|c|c|}
\hline Authors & Program & Main Finding & Issues Covered \\
\hline $\begin{array}{l}\text { Bourguignon and } \\
\text { others (2002) }\end{array}$ & $\begin{array}{l}\text { Bolsa Escola } \\
\text { (Brazil) }\end{array}$ & $\begin{array}{l}\text { - Ex-ante evaluation of the program showed } \\
\text { increases in school enrollment, with larger } \\
\text { effects for poor households. } \\
\text { - No effect on current poverty levels } \\
\text { - Unconditional cash transfers would have } \\
\text { no impact on child labor and school } \\
\text { enrollment rates }\end{array}$ & $\begin{array}{l}\text { Implementation, targeting, } \\
\text { redistribution. }\end{array}$ \\
\hline $\begin{array}{l}\text { Cardoso and Souza } \\
(2003)\end{array}$ & $\begin{array}{l}\text { Bolsa Escola } \\
\text { (Brazil) }\end{array}$ & $\begin{array}{l}\text { - No impact on child labor, but positive } \\
\text { impact on enrollment. }\end{array}$ & Targeting, fungibility, efficiency. \\
\hline $\begin{array}{l}\text { Galasso and } \\
\text { Ravallion (2002) }\end{array}$ & $\begin{array}{l}\text { Food for Education } \\
\text { (Bangladesh) }\end{array}$ & - Program mildly pro-poor. & Targeting, efficiency \\
\hline $\begin{array}{l}\text { Galasso and } \\
\text { Ravallion (2003) }\end{array}$ & $\begin{array}{l}\text { Plan Jefes y Jefas } \\
\text { (Argentina) }\end{array}$ & $\begin{array}{l}\text { Well-targeted program with significant } \\
\text { impact on poverty reduction } \\
\text { Foregone incomes equal roughly one-third } \\
\text { of the cash transfer provided by the plan. }\end{array}$ & $\begin{array}{l}\text { Targeting, redistribution, equity- } \\
\text { efficiency trade-off }\end{array}$ \\
\hline Jacoby (1997) & $\begin{array}{l}\text { Nutribun and Milk } \\
\text { Program (Jamaica) }\end{array}$ & $\begin{array}{l}\text { Poorest households receive the largest } \\
\text { benefits. } \\
\text { However, benefits per beneficiary child } \\
\text { are less than } 50 \% \text { of program cost, } \\
\text { suggesting considerable deadweight loss. }\end{array}$ & Targeting, redistribution, efficiency \\
\hline
\end{tabular}




\begin{tabular}{|c|c|c|c|}
\hline Authors & Program & Main Finding & Issues Covered \\
\hline Jacoby (2002) & $\begin{array}{l}\text { School Feeding } \\
\text { Program } \\
\text { (Philippines) }\end{array}$ & $\begin{array}{l}\text { - On school days, the calorie intake of } \\
\text { children is higher by } 80 \% \text { of the caloric } \\
\text { value from the school feeding program. } \\
\text { - Effects weaker for children in poorer } \\
\text { households. }\end{array}$ & Fungibility, redistribution \\
\hline $\begin{array}{l}\text { Khandker and } \\
\text { others (2003) }\end{array}$ & $\begin{array}{l}\text { Female Stipend } \\
\text { Program } \\
\text { (Bangladesh) }\end{array}$ & $\begin{array}{l}\text { - Girls' secondary education increased } \\
\text { substantially, while boys' education } \\
\text { decreased in some instances } \\
\text { - Benefits from the program accrued } \\
\text { disproportionately to girls from } \\
\text { households with large landholdings. }\end{array}$ & $\begin{array}{l}\text { Implementation, equity-efficiency } \\
\text { trade-off, fungibility }\end{array}$ \\
\hline $\begin{array}{l}\text { Kremer and Miguel } \\
(2003)\end{array}$ & $\begin{array}{l}\text { Western Kenya } \\
\text { Deworming Project }\end{array}$ & $\begin{array}{l}\text { - Negative social learning effects lead to } \\
\text { "free-riding" due to the positive } \\
\text { externalities of deworming treatment } \\
\text { - Need to continue subsidies indefinitely }\end{array}$ & Learning externalities \\
\hline $\begin{array}{l}\text { Miguel and Kremer } \\
\text { (2003a) }\end{array}$ & $\begin{array}{l}\text { Western Kenya } \\
\text { Deworming Project }\end{array}$ & $\begin{array}{l}\text { - Positive School participation increased in } \\
\text { control group. } \\
\text { - Externalities for students in treatment } \\
\text { schools and neighboring schools. }\end{array}$ & $\begin{array}{l}\text { Implementation, physical } \\
\text { externalities, cost-effectiveness }\end{array}$ \\
\hline
\end{tabular}




\begin{tabular}{|c|c|c|c|}
\hline Authors & Program & Main Finding & Issues Covered \\
\hline $\begin{array}{l}\text { Miguel and Kremer } \\
(2003 b)\end{array}$ & $\begin{array}{l}\text { Western Kenya } \\
\text { Deworming Project }\end{array}$ & $\begin{array}{l}\text { Small increase in price of deworming pills } \\
\text { lead to large reduction in take-up rates. } \\
\text { - Health education and community } \\
\text { mobilization programs failed. } \\
\text { - Latrines and boreholes were far less cost- } \\
\text { effective than provision of deworming } \\
\text { pills. }\end{array}$ & $\begin{array}{l}\text { Implementation, cost-effectiveness } \\
\text { of program vs. alternative } \\
\text { counterfactuals }\end{array}$ \\
\hline $\begin{array}{l}\text { Ravallion and } \\
\text { Wodon (2000) }\end{array}$ & $\begin{array}{l}\text { Food for Education } \\
\text { (Bangladesh) }\end{array}$ & $\begin{array}{l}\text { - Program increased schooling. } \\
\text { - This increase was far more than the } \\
\text { decrease in child labor. }\end{array}$ & $\begin{array}{l}\text { Implementation, equity-efficiency } \\
\text { trade-off, fungibility }\end{array}$ \\
\hline Schultz (2001) & $\begin{array}{l}\text { PROGRESA } \\
\text { (Mexico) }\end{array}$ & $\begin{array}{l}\text { - Positive impact on school attainment. } \\
\text { - For most families in rural Mexico, the } \\
\text { effect is a wealth effect. }\end{array}$ & $\begin{array}{l}\text { Implementation, equity-efficiency } \\
\text { trade-off, fungibility }\end{array}$ \\
\hline $\begin{array}{l}\text { Stifel and Alderman } \\
(2003)\end{array}$ & $\begin{array}{l}\text { Vaso de Leche } \\
\text { (Peru) }\end{array}$ & $\begin{array}{l}\text { Program well-targeted to the poor and has } \\
\text { minimal leakage. } \\
\text { - No impact on the main goal of increasing } \\
\text { child height. }\end{array}$ & $\begin{array}{l}\text { Targeting, fungibility, } \\
\text { implementation. }\end{array}$ \\
\hline
\end{tabular}

